\title{
Genetic structure and effective population size of the most northern population of the Australian River Blackfish, Gadopsis marmoratus (Richardson 1848): implications for long-term population viability
}

\author{
Joel A. Huey ${ }^{1,2,3,4,5}$, Stephen R. Balcombe ${ }^{4,6}$, Kathryn M. Real ${ }^{4,7}$, David Sternberg ${ }^{4,8}$, \\ and Jane M. Hughes ${ }^{4,9}$ \\ ${ }^{1}$ Department of Terrestrial Zoology, Western Australian Museum, Locked Bag 49, Welshpool DC, Western Australia 6986 Australia \\ ${ }^{2}$ School of Animal Biology, University of Western Australia, Crawley, Western Australia 6009 Australia \\ ${ }^{3}$ School of Natural Sciences, Edith Cowan University, Joondalup, Western Australia 6027 Australia \\ ${ }^{4}$ Australian Rivers Institute, Griffith University, Nathan, Queensland 4111 Australia
}

\begin{abstract}
Upland freshwater habitats support populations that are especially susceptible to anthropogenic change. Furthermore, their isolation from other suitable habitats, and the fragmented, dendritic structure of headwaters make dispersal an unlikely response to change. We investigated genetic structure and variation in the northernmost population of Gadopsis marmoratus, which is isolated in a tiny area in the headwaters of the Condamine River catchment, in the Murray-Darling Basin, Australia. Strong genetic structure was detected among subpopulations based on microsatellites $\left(F_{\mathrm{ST}}=0.173, p<0.0001\right)$ and mitochondrial $(\mathrm{mt}) \mathrm{DNA}\left(F_{\mathrm{ST}}=0.369, p<0.05\right)$. Effective population size was low, ranging between 18.8 and 48.2, depending on the estimation method used. Bayesian clustering revealed 3 genetic clusters, but they were not congruent with drainage patterns, suggesting a complex history of dispersal among headwaters that are isolated by waterfalls. Overall, these results suggest that G. marmoratus is unlikely to disperse into new habitats if local conditions become unsuitable. Low effective population size and genetic diversity also suggest that local adaptation would be unlikely.
\end{abstract}

Key Words: gene flow, connectivity, waterfalls, freshwater fish, conservation genetics, microsatellites, mitochondrial DNA, Australia

Freshwater fish often inhabit naturally fragmented landscapes where gene flow is restricted. As a result, genetic diversity is often low, and subpopulations are genetically distinct (Ward et al. 1994, DeWoody and Avise 2000). This situation is especially true of species that are restricted to mountainous headwater streams (Hughes et al. 2013). Soft barriers, such as temperature, small waterfalls, and steep stream gradients can decrease gene flow among subpopulations (Cook et al. 2011) or cause it to be strongly unidirectional (Kelson et al. 2014), whereas hard barriers, such as large waterfalls, may halt all migration, thereby causing strong divergence and speciation (McGlashan and Hughes 2000). In addition to these processes are the more infrequent effects of geological change (e.g., drainage rearrangements; Poissant et al. 2005, Waters et al. 2001), and human mediated dispersal and colonization (Waples 1991). These processes interact with the physiology and behavior of freshwater fish species to determine patterns of genetic variation at neutral loci.

By studying these patterns of genetic variation, one can understand how these species disperse through a fragmented landscape and how they maintain population viability. This consideration is important from a conservation perspective. Freshwater systems are becoming more fragmented because of habitat clearing, flow regulation infrastructure, and degraded water quality, and species restricted to colder, upland areas will be seriously affected by climate change (Nilsson et al. 2005, Ficke et al. 2007, Palmer et al. 2008). The negative effects are 2-fold. First, small population sizes and low gene flow will decrease genetic variation and adaptive potential, reducing the capacity for species to adapt to the changing environment (Willi et al. 2006). Second, range expansions

E-mail: ${ }^{5}$ joel.huey@museum.wa.gov.au; ${ }^{6}$ s.balcombe@griffith.edu.au; ${ }^{7}$ k.real@griffith.edu.au; ${ }^{8}$ david.sternberg@dnrm.qld.gov.au; ${ }^{9}$ jane.hughes@griffith .edu.au

DOI: 10.1086/690557. Received 5 September 2015; Accepted 22 September 2016; Published online 4 January 2017.

Freshwater Science. 2017. 36(1):113-123. ๑ 2017 by The Society for Freshwater Science. 
to more suitable habitat are difficult for species that are strongly constrained by the dendritic riverine network (Hein et al. 2011).

Populations may respond to threats by adapting to their changing environment. However, the small effective population size and low genetic variation of fragmented species make adaptation difficult. Genetic drift becomes the dominant evolutionary force and can have a more significant effect than selection when effective population sizes are small. Therefore, in very small populations, deleterious alleles can be maintained, increasing inbreeding depression and the genetic load on the population (Wang et al. 1999, Kirkpatrick and Jarne 2000). In addition, small populations have lower levels of standing genetic variation and reduced probability of advantageous mutations arising, also reducing adaptive capacity, than larger populations (Willi et al. 2006).

In Australia, researchers investigating headwater populations of freshwater fish (Hurwood and Hughes 1998, McGlashan and Hughes 2000) and upland- and coldwater-adapted crustaceans (Hughes et al. 1995, 1996, Hurwood and Hughes 2001, Ponniah and Hughes 2006) have found strong genetic structure. For many of these species, contemporary gene flow was mostly absent, but patterns of genetic structure were unexpected and matched historical patterns of connectivity across catchment boundaries.

The River Blackfish (Gadopsis marmoratus Richardson 1848) has a broad distribution throughout the Murray-Darling Basin (MDB) and coastal drainages in the southeastern part of the continent. In the MDB, it is mostly found in the southern parts of the basin. Populations in the northern basin are restricted to upland reaches that flow off the Great Dividing Range (Lintermans 2007). Based on molecular data, G. marmoratus may comprise multiple species (Miller et al. 2004, Hammer et al. 2014). Tracking studies of G. marmoratus demonstrate that adults are likely to disperse some distance up- and downstream at night, but that individuals return to the same location during the day (Koster and Crook 2008). In addition, spawning occurs in logs and under rocks, and eggs are demersal (Lintermans 2007). Larvae remain attached to their egg case for $\sim 18 \mathrm{~d}$, remain burrowed into the substrate (e.g., in leaf litter), and probably are guarded by the parent male during this period (Koehn and O'Connor 1990a). Thus, they are unlikely to drift during the period of lowest swimming ability. Probably only late-stage larvae or juveniles are capable of dispersal, especially via downstream displacement in steep, fast-flowing streams such as during highflow events. This life history suggests that gene flow among subpopulations may be low, and genetic structure should be strong.

The northern-most population of G. marmoratus is found in the upper reaches of the Condamine River catchment, in southeastern Queensland (Fig. 1A, B). The most intact populations in this catchment occur within the Spring Creek tributaries of the Condamine River. Spring Creek consists of a north and south branch, and both have significant waterfalls. The north branch has 2 major waterfalls (Queen Mary and Daggs Falls), whereas the south branch has Browns and Upper Browns Falls. Both branches are spring-fed and run through intact forest, especially in the most upland regions. The forest keeps Spring Creek stream temperatures lower than those of the upper reaches of the Condamine River (M. Turschwell, Griffith University, unpublished data).

In this population, the existence of strong unidirectional barriers to gene flow (waterfalls) is likely to shape genetic variation among subpopulations. Under this model, subpopulations that exist in headwaters above waterfalls are expected to diverge from each other in the absence of immigration from downstream subpopulations. If downstream dispersal
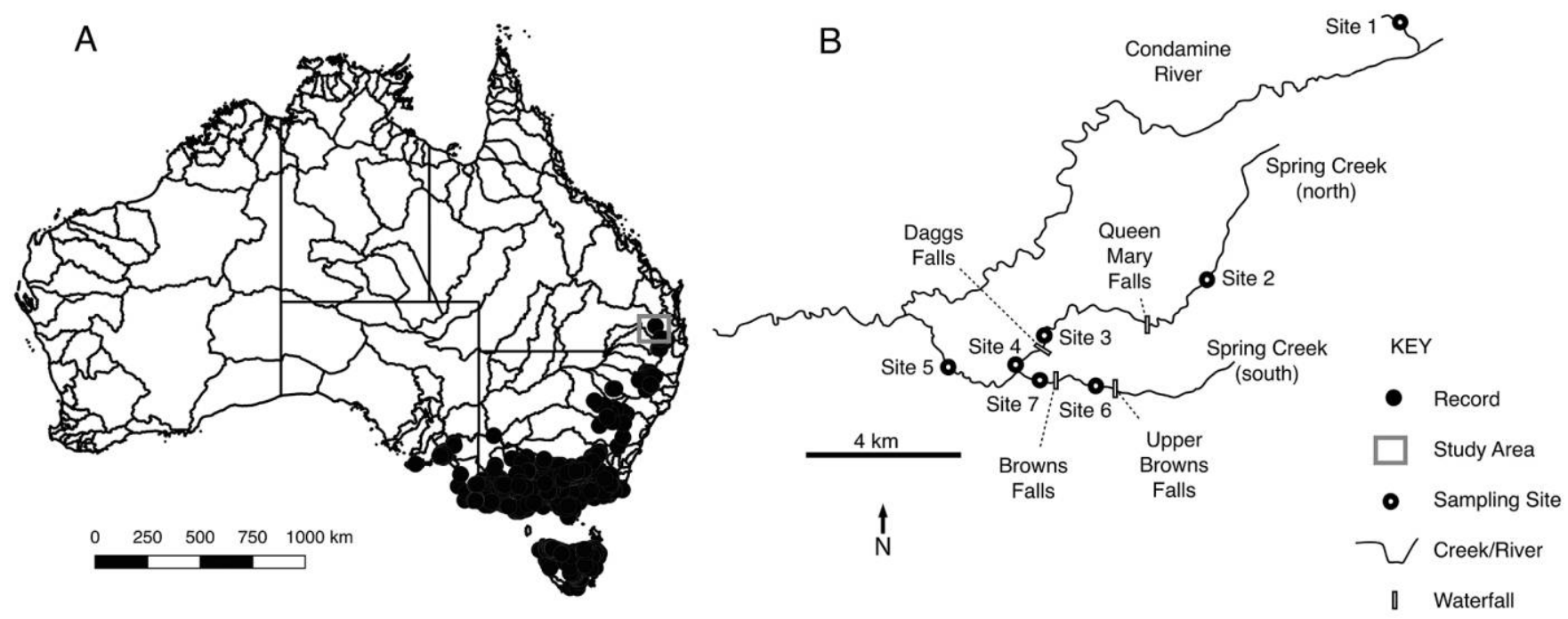

Figure 1. Summary of records of Gadopsis marmoratus in Australia (www.ala.org.au) (A) and a map of the study area, showing the 4 main waterfalls and sampling sites (B). See Table 1 for sampling site coordinates. 
is possible, subpopulations that are downstream of isolated populations may be admixed, composed of local recruits and migrants from different, genetically distinct, headwater populations. The magnitude of genetic differentiation among headwater subpopulations depends on how long headwater subpopulations have been isolated, their effective population size, and if rare dispersal events (e.g., river re-arrangements, or human-mediated dispersal) have occurred.

We used mitochondrial (mt)DNA and microsatellites to explore the genetic structure of G. marmoratus in the upper reaches of the Condamine catchment (Spring Creek and the Condamine River). Our objectives were to assess the overall dispersal ability of this species in an isolated and vulnerable population and to identify the role of waterfalls in shaping genetic structure.

\section{METHODS}

\section{Sampling and field work}

We chose 13 sampling locations to represent the distributional range of G. marmoratus in the Upper Condamine River catchment in May 2010. The main sites where G. marmoratus occurred were in the Spring Creek tributaries (north and south branch) where stream width was on average $2 \mathrm{~m}$ wide and substrate consisted of a mix of cobbles, bedrock, and finer sediments. Most of the study area has been cleared for pastoral grazing, and riparian widths generally are limited. Four large waterfalls exist within the sampling area on Spring Creek. They range in height between 10 (Lower Browns Falls) and 40 m (Queen Mary Falls) (S. Balcombe, personal observation). The height of the other 2 waterfalls is similar to that of Queen Mary Falls. The elevational gradient ranges from $\sim 850 \mathrm{~m}$ asl at Queen Mary Falls to $520 \mathrm{~m}$ at Killarney below the confluence of Spring Creek with the Condamine River.

We fished with the aid of a portable backpack electrofisher (Mk 12 POW; Smith-Root, Vancouver, Washington) in an upstream direction for $\sim 80 \mathrm{~m}$ at each site. We used the electrofisher for $\sim 5$ to $10 \mathrm{~s}$ (depending on the size and spe- cies of fish) to stun fish temporarily and collected all stunned fish with a fine-mesh hand-net and immediately placed them in a 70-L plastic container containing stream water. We finclipped and immediately returned a subset of G. marmoratus to the water. Up to 20 samples were taken at sites where G. marmoratus were caught, except at 1 site, where we retained 56 fin clips. We stored fin-clips in 70\% ethanol for genetic analyses. We added samples from another site 1 on the Condamine River (site 1) to those we collected (collected by A. Butcher, Queensland Fisheries).

\section{Molecular methods}

We used fin clips from 155 fish collected across 6 sites in Spring Creek and 1 site in the upper Condamine River (Table 1, Fig. 1). We used salt (Aljanabi and Martinez 1997) to extract total genomic DNA, which we subsequently diluted in $50 \mu \mathrm{L}$ of double-distilled $\mathrm{H}_{2} \mathrm{O}$ and kept at $4^{\circ} \mathrm{C}$ until required for further analysis.

We amplified 2 mtDNA loci, ATPase (ATP, subunits 6 and 8 ) and Cytochrome B (CytB) from 11 to 20 individuals per site. We used LYS.31F and $\mathrm{HCH}$ primers to amplify the ATP locus (P. J. Unmack, Institute for Applied Ecology, University of Canberra, unpublished data; Page and Hughes 2010) and HYPSLA and HYPSHD primers to amplify CytB (Thacker et al. 2007). Amplification protocols followed those of Page and Hughes (2010) and Thacker et al. (2007), respectively. We purified the amplified product and direct-sequenced it at the Griffith University sequencing facility on a 3130xl Genetic Analyzer (Applied Biosystems, Foster City, California).

We screened 13 previously published microsatellite loci for variation in a subset of individuals (Arias et al. 2013). This screening revealed 12 loci that amplified consistently, but only 10 that were polymorphic (Gama01-Gama10; Molecular Ecology Resources primer database numbers 5072550734). We subsequently amplified these loci from all individuals. Amplification protocols followed Huey et al. (2011), with annealing temperatures of each locus following the details found on the MER primer database. We ran polymer-

Table 1. Site details, including coordinates and samples sizes $(n) . H=$ gene diversity for mitochondrial (mt)DNA data. $\pi=$ nucleotide diversity for mtDNA data. msats $=$ microsatellites

\begin{tabular}{lcccccc}
\hline Site number & Latitude & Longitude & $n$ (msats) & $n$ (mtDNA) & $H$ (mtDNA) & $\pi(\mathrm{mtDNA})$ \\
\hline 1 & 28.25613 & -152.44257 & 11 & 11 & 0.00 & 0.00000 \\
2 & 28.32917 & -152.38986 & 19 & 18 & 0.50 & 0.00099 \\
3 & 28.34292 & -152.41888 & 19 & 19 & 0.28 & 0.00083 \\
4 & 28.34977 & -152.33871 & 20 & 20 & 0.47 & 0.00087 \\
5 & 28.3499 & -152.32083 & 10 & 10 & 0.00 & 0.00000 \\
6 & 28.35435 & -152.35999 & 20 & 20 & 0.00 & 0.00000 \\
7 & 28.35299 & -152.34488 & 56 & 20 & 0.00 & 0.00000 \\
Total & & & 155 & 118 & - & - \\
Mean & & & 22.14 & 16.86 & 0.18 & 0.00038
\end{tabular}


ase chain reactions individually then pooled them for screening on an ABI 3130 Genetic Analyzer per the manufacturers recommendations. We used GeneMapper (version 4.0; Applied Biosystems) to score microsatellite loci.

\section{Statistical analysis}

We calculated genetic diversity for mtDNA as gene diversity and nucleotide diversity in the program Arlequin (version 3.5.1; Excoffier and Lischer 2010). We calculated expected heterozygosity for microsatellites in Arlequin and allelic richness and private allelic richness in ADZE (version 1.0; Szpiech et al. 2008). We tested genotypes for conformance to expectations under Hardy-Weinberg equilibrium in Arlequin.

To explore the loss of genetic variation and adaptive potential in this headwater population, we estimated the effective population size $\left(\mathrm{N}_{\mathrm{e}}\right)$ at site 7 , which we sampled more intensively than the other sites. We used an approximate Bayesian computation (ABC) method (onesAmp; Tallmon et al. 2008) and linkage disequilibrium (LD) (NeEstimator;
Waples and Do 2008, Do et al. 2014) to estimate $\mathrm{N}_{\mathrm{e}}$. ONeSAMP simulates populations of different effective sizes and draws data sets from them, matching the configuration of the observed data. Summary statistics are calculated for the simulated data sets and compared to the summary statistics for the observed data set to produce a posterior distribution of $\mathrm{N}_{\mathrm{e}}$. The LD approach uses the expected increase in LD in smaller populations to estimate $\mathrm{N}_{\mathrm{e}}$.

We estimated the evolutionary relationships between mtDNA haplotypes based on a parsimony network, calculated in TCS (version 1.21; Clement et al. 2000). This approach allowed us to visualize genetic variation across the river network and to identify highly divergent sites/creeks. We estimated genetic differentiation for mtDNA and microsatellites as the fixation index $\left(F_{\mathrm{ST}}\right)$, calculated in Arlequin. For mtDNA, we used the $F_{\mathrm{ST}}$ analog, $\Phi_{\mathrm{ST}}$.

We used a Bayesian clustering method in the program STRUCTURE (version 2.3.2; Pritchard et al. 2000) to identify genetic clusters (or populations) based on the microsatellite data and the admixture model (2 million steps after a burn-in of 50,000 steps) with the loc prior function, which

Table 2. Heterozygosity, allelic richness, and private allelic richness for microsatellite loci. Allelic richness and private allelic richness data were rarified for $n=6$. Bold indicates site/locus combinations significantly out of Hardy-Weinberg equilibrium $(p<0.05)$.

\begin{tabular}{|c|c|c|c|c|c|c|c|c|c|c|c|}
\hline Site & $\begin{array}{c}\text { Gamma } \\
01\end{array}$ & $\begin{array}{c}\text { Gamma } \\
02\end{array}$ & $\begin{array}{c}\text { Gamma } \\
03\end{array}$ & $\begin{array}{c}\text { Gamma } \\
04\end{array}$ & $\begin{array}{c}\text { Gamma } \\
05\end{array}$ & $\begin{array}{c}\text { Gamma } \\
06\end{array}$ & $\begin{array}{c}\text { Gamma } \\
07\end{array}$ & $\begin{array}{c}\text { Gamma } \\
08\end{array}$ & $\begin{array}{c}\text { Gamma } \\
09\end{array}$ & $\begin{array}{c}\text { Gamma } \\
10\end{array}$ & Mean \\
\hline \multicolumn{12}{|c|}{ Heterozygosity } \\
\hline 1 & 0.000 & 0.000 & 0.000 & 0.000 & 0.000 & 0.000 & 0.000 & 0.000 & 0.294 & 0.000 & 0.029 \\
\hline 2 & 0.000 & 0.000 & 0.102 & 0.422 & 0.102 & 0.212 & 0.193 & 0.434 & 0.000 & 0.000 & 0.147 \\
\hline 3 & 0.337 & 0.000 & 0.323 & 0.371 & 0.000 & 0.214 & 0.000 & 0.413 & 0.000 & 0.000 & 0.166 \\
\hline 4 & 0.166 & 0.385 & 0.053 & 0.513 & 0.063 & 0.203 & 0.431 & 0.622 & 0.000 & 0.356 & 0.279 \\
\hline 5 & 0.000 & 0.000 & 0.000 & 0.505 & 0.111 & 0.567 & 0.209 & 0.616 & 0.000 & 0.000 & 0.201 \\
\hline 6 & 0.000 & 0.000 & 0.000 & 0.296 & 0.000 & 0.102 & 0.097 & 0.199 & 0.000 & 0.000 & 0.070 \\
\hline 7 & 0.000 & 0.120 & 0.000 & 0.392 & 0.217 & 0.122 & 0.404 & 0.638 & 0.000 & 0.018 & 0.191 \\
\hline \multicolumn{12}{|c|}{ Allelic richness } \\
\hline 1 & 1.00 & 1.00 & 1.00 & 1.00 & 1.00 & 1.00 & 1.00 & 1.00 & 1.73 & 1.00 & 1.07 \\
\hline 2 & 1.00 & 1.00 & 1.29 & 1.89 & 1.29 & 1.56 & 1.51 & 2.20 & 1.00 & 1.00 & 1.38 \\
\hline 3 & 1.78 & 1.00 & 1.76 & 1.83 & 1.00 & 1.56 & 1.00 & 1.88 & 1.00 & 1.00 & 1.38 \\
\hline 4 & 1.45 & 1.85 & 1.16 & 1.98 & 1.19 & 1.53 & 1.90 & 2.58 & 1.00 & 1.81 & 1.64 \\
\hline 5 & 1.00 & 1.00 & 1.00 & 1.98 & 1.33 & 2.51 & 1.57 & 2.50 & 1.00 & 1.00 & 1.49 \\
\hline 6 & 1.00 & 1.00 & 1.00 & 1.71 & 1.00 & 1.29 & 1.28 & 1.59 & 1.00 & 1.00 & 1.19 \\
\hline 7 & 1.00 & 1.33 & 1.00 & 1.85 & 1.55 & 1.36 & 1.86 & 2.63 & 1.00 & 1.05 & 1.46 \\
\hline \multicolumn{12}{|c|}{ Private allelic richness } \\
\hline 1 & 0.00 & 0.00 & 0.00 & 0.00 & 0.00 & 0.00 & 0.00 & 0.00 & 0.73 & 0.00 & 0.07 \\
\hline 2 & 0.00 & 0.00 & 0.06 & 0.00 & 0.07 & 0.06 & 0.00 & 0.00 & 0.00 & 0.00 & 0.02 \\
\hline 3 & 0.43 & 0.00 & 0.45 & 0.00 & 0.00 & 0.06 & 0.00 & 0.00 & 0.00 & 0.00 & 0.09 \\
\hline 4 & 0.10 & 0.56 & 0.03 & 0.00 & 0.04 & 0.05 & 0.00 & 0.00 & 0.00 & 0.76 & 0.15 \\
\hline 5 & 0.00 & 0.00 & 0.00 & 0.00 & 0.09 & 0.39 & 0.00 & 0.00 & 0.00 & 0.00 & 0.05 \\
\hline 6 & 0.00 & 0.00 & 0.00 & 0.00 & 0.00 & 0.02 & 0.00 & 0.00 & 0.00 & 0.00 & 0.00 \\
\hline 7 & 0.00 & 0.05 & 0.00 & 0.00 & 0.21 & 0.02 & 0.00 & 0.00 & 0.00 & 0.01 & 0.03 \\
\hline
\end{tabular}


Table 3. Estimates of effective population size $\left(\mathrm{N}_{\mathrm{e}}\right)$ based on approximate Bayesian computation $(\mathrm{ABC})$ and linkage disequilibrium $(\mathrm{LD}) . \mathrm{CL}=$ confidence limit.

\begin{tabular}{lccc}
\hline \multicolumn{1}{c}{ Method } & $\mathrm{N}_{\mathrm{e}}$ & $\begin{array}{r}\text { Lower } \\
95 \% \mathrm{CL}\end{array}$ & $\begin{array}{r}\text { Upper } \\
95 \% \mathrm{CL}\end{array}$ \\
\hline $\begin{array}{l}\text { ABC } \\
\quad \text { Prior of } \mathrm{N}_{\mathrm{e}}\end{array}$ & & & \\
$\quad 2$ to 50 & 21.5 & 14.8 & 36.8 \\
$\quad 2$ to 100 & 23.7 & 16.5 & 41.7 \\
$\quad 2$ to 200 & 18.8 & 13.2 & 39.9 \\
LD $\quad$ & & \\
Lowest frequency & & & \\
$\quad$ allele used & & & \\
$\quad 0.05$ & 48.2 & 3.7 & $\infty$ \\
0.02 & 37.9 & 4.6 & $\infty$ \\
0.01 & 34.3 & 4.0 & $\infty$ \\
0 & 38.8 & 7.2 & $\infty$ \\
\hline
\end{tabular}

uses the sampling location as a prior in the model. Default settings were used for all other functions. We made 5 replicate runs for $K=1$ to 7 , which allowed us to identify the most likely number of genetic clusters in the data set. We used the method outlined by Evanno et al. (2005) and carried out in STRUCTURE HARVESTER (version 0.6.94; Earl 2012) to choose the most likely number of genetic clusters.

Based on the dendritic structure of the upper Condamine and Spring Creek drainages, we expected to observe unidirectional contemporary gene flow. We tested this expectation with the program BayesAss (version 3; Wilson and Rannala 2003), which uses a Bayesian framework to estimate the migration rate among populations, averaged across the previous 3 to 4 generations.

\section{RESULTS}

mtDNA sequencing revealed only 3 haplotypes across 1018 basepairs (bp) of sequence. Gene diversity ranged from 0 to 0.50 , and nucleotide diversity ranged from 0 to 0.00099
(Table 1). For microsatellites, expected heterozygosity, averaged across loci for a site, ranged from 0.029 to 0.279 (Table 2). Of the 70 loci/site combinations, 33 were fixed for a single allele. Allelic richness was low, and private allelic richness showed few sites that had unique genetic variation (Table 2). The low genetic diversity was matched by estimates of $\mathrm{N}_{\mathrm{e}}$ (Table 3). ABC estimates were $\sim 19$ to $\sim 24$, with credible intervals between $\sim 13$ and $\sim 42$. LD estimates were higher (34-48), but highly imprecise, with confidence intervals ranging from 4 to $\infty$.

Sites were strongly structured (Table 4). For mtDNA, global $F_{\mathrm{ST}}$ was 0.369 and was significantly different from $0(p<0.05)$. For microsatellites, global $F_{\mathrm{ST}}$, averaged across loci, was 0.173 and significantly different from $0(p<0.0001)$. Pairwise $F_{\mathrm{ST}}$ values for microsatellites revealed significant genetic structure for all pairwise comparisons, except for the comparison between sites 2 and 6 , which were isolated above waterfalls.

We found support for 3 genetic clusters that were geographically partitioned (Fig. 2A). One cluster (gray) was restricted to the downstream sites below waterfalls. A $2^{\text {nd }}$ cluster (white) was found at sites above waterfalls in headwaters that were separated by lowland sites. The ancestry of individuals was not fixed to a single cluster, and individuals with ancestry from $>1$ cluster were found at each site. For example, most individuals from site 6 had ancestry in the 'white' cluster, but some did not. Individuals from the downstream site 7 were assigned predominantly to the 'gray' cluster, but all individuals had a small proportion of their ancestry $(<50 \%)$ assigned to the white cluster.

Patterns of genetic variation for microsatellites did not align perfectly with mtDNA data (Fig. 2B). Low variation led to an inability to distinguish among many of the Spring Creek sites. All individuals at site 1 shared a single haplotype, which was also found in lower frequencies at site 3 ('black' microsatellite cluster) and site 4 ('gray' microsatellite cluster). Sites in the northern branch of Spring Creek had the highest genetic variation, and harbored a unique haplotype.

Contemporary gene flow, estimated using BayesAss, was low. Five sites showed significant evidence of immigration

Table 4. Pairwise fixation index $\left(F_{\mathrm{ST}}\right)$ values. Above diagonal $=$ mitochondrial $(\mathrm{mt}) \mathrm{DNA}$, below diagonal $=$ microsatellites. ${ }^{*}=p<0.05$.

\begin{tabular}{lccccccc}
\hline Site & 1 & 2 & 3 & 4 & 5 & 6 & 7 \\
\hline 1 & - & $0.665^{*}$ & $0.794^{*}$ & $0.629^{*}$ & $1.000^{*}$ & $1.000^{*}$ & $1.000^{*}$ \\
2 & $0.181^{*}$ & - & $0.295^{*}$ & 0.000 & 0.276 & $0.369^{*}$ & $0.369^{*}$ \\
3 & $0.499^{*}$ & $0.200^{*}$ & - & $0.435^{*}$ & $0.714^{*}$ & $0.776^{*}$ & $0.776^{*}$ \\
4 & $0.305^{*}$ & $0.122^{*}$ & $0.112^{*}$ & - & 0.120 & $0.191^{*}$ & 0.191 \\
5 & $0.613^{*}$ & $0.351^{*}$ & $0.431^{*}$ & $0.193^{*}$ & - & 0.000 & 0.000 \\
6 & $0.141^{*}$ & 0.009 & $0.342^{*}$ & $0.220^{*}$ & $0.503^{*}$ & - & 0.000 \\
7 & $0.249^{*}$ & $0.072^{*}$ & $0.231^{*}$ & $0.084^{*}$ & $0.172^{*}$ & $0.147^{*}$ & - \\
\hline
\end{tabular}


A

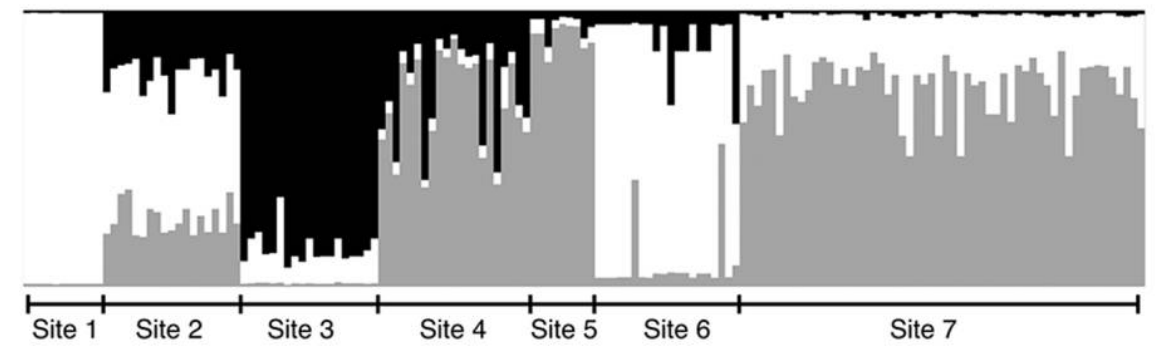

B

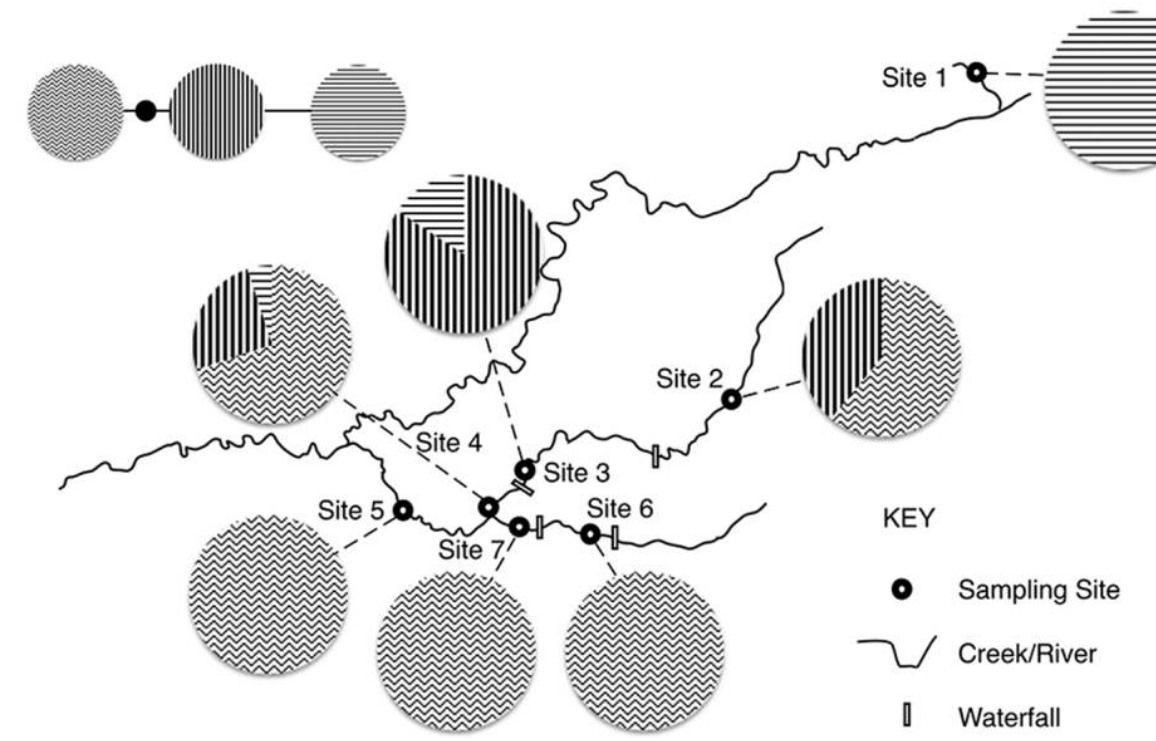

Figure 2. A.-Bar graph showing the proportion of ancestry for each individual attributable to the 3 genetic clusters identified with STRUCTURE analysis. B.-Mitochondrial (mt)DNA haplotype network and haplotype frequencies for Gadopsis marmoratus at each sampling site. Pie diagrams show the relative frequency of each haplotype in each sampling site.

(Table 5), but patterns did not match the dendritic structure of the river network (Fig. 3). Both headwater sites (sites 1 and 2) had evidence of immigration from sites 6 and 7. Below the waterfalls, sites were connected by immigration (site 7 into sites 4 and 5). Downstream gene flow was detected across only 1 waterfall, from site 2 into site 3.

\section{DISCUSSION}

Land clearing, grazing, recreational vehicle usage, and climate change are all threats to upland freshwater ecosystems (Swift and Messer 1971, Wohl 2006, Arp and Simmons 2012, Herbst et al. 2012, Isaak et al. 2012), and many headwater species are in threat of extinction worldwide (Poff et al. 2012). Populations may respond to threats by adapting to their changing environment, but if a population is unable to adapt in situ, the range of a species may change in response to poor local conditions. This mechanism has been suggested for many species threatened by climate change (e.g., Chu et al. 2005). Subpopulations situated in suboptimal environments typically become nonviable, while the species' range extends into newly available habitats. For example, many temperate species in the northern hemisphere have extended their range north or uphill as temperatures have become milder (Hickling et al. 2006). For species with

Table 5. Summary of BayesAss analysis. Comparisons for which 95\% confidence intervals that did not overlap with 0 (i.e., site comparisons with significant unidirectional gene flow) are shown. These results are visually represented in Fig. 3. $m=$ migration rate, $\mathrm{CI}=$ confidence interval.

\begin{tabular}{lcccc}
\hline Source site & Sink site & $m$ & $\begin{array}{c}\text { Lower } \\
95 \% \text { CI }\end{array}$ & $\begin{array}{c}\text { Upper } \\
95 \% \text { CI }\end{array}$ \\
\hline 2 & 3 & 0.211 & 0.147 & 0.275 \\
7 & 2 & 0.112 & 0.029 & 0.194 \\
7 & 4 & 0.122 & 0.036 & 0.207 \\
7 & 5 & 0.178 & 0.070 & 0.285 \\
6 & 2 & 0.130 & 0.024 & 0.236 \\
6 & 1 & 0.220 & 0.123 & 0.317 \\
\hline
\end{tabular}




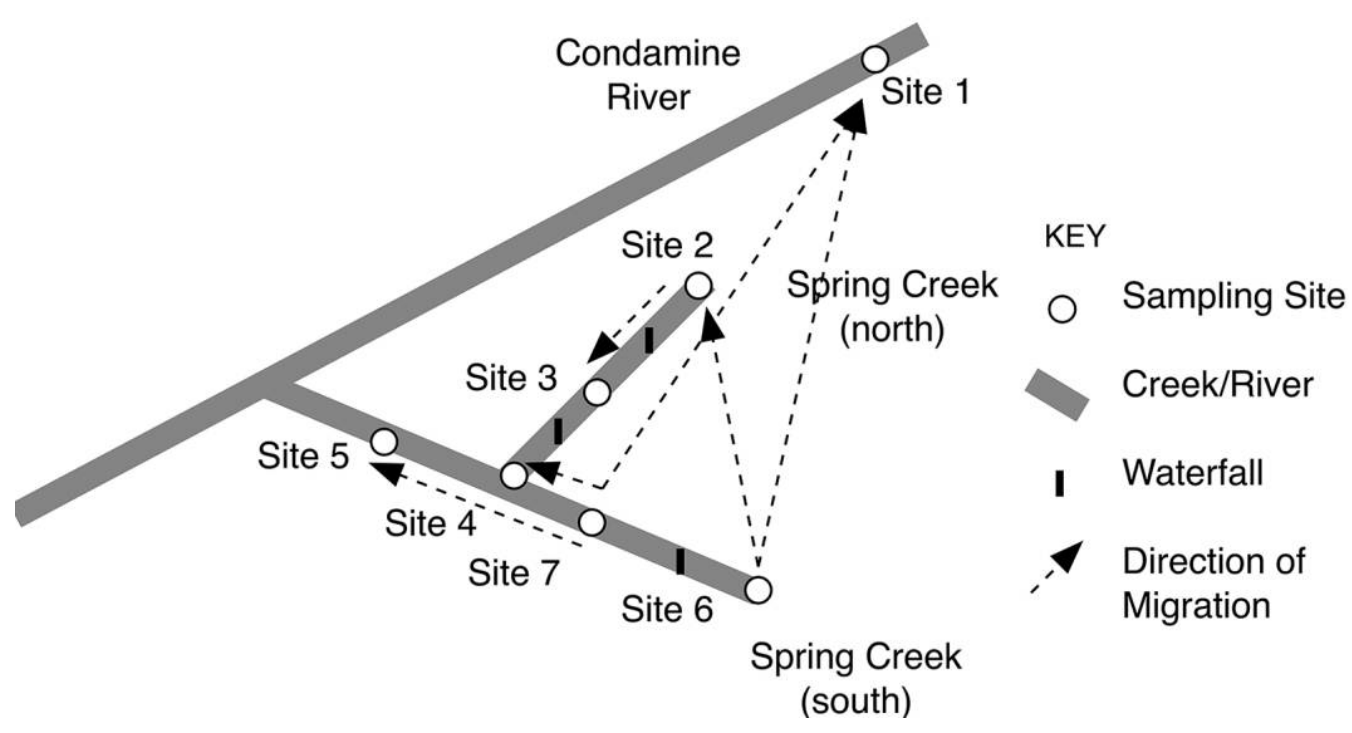

Figure 3. Summary of BayesAss results, showing dominant patterns of gene flow in the study area. See Table 5 for migration rates.

little dispersal capacity, the rate of colonization may not be rapid enough to prevent extinction.

By exploring the genetic diversity and genetic structure of G. marmoratus, we can identify its capacity to either adapt to change in situ or its ability to disperse to more suitable areas if local conditions become unsuitable. Our data indicate a number of key threats to the long-term viability of the northern-most population of G. marmoratus.

\section{Low genetic variation and low $\mathrm{N}_{\mathrm{e}}$}

Populations at all sites exhibited low genetic variation at mtDNA and nuclear DNA loci. Many microsatellite loci were fixed for a single allele in multiple populations. This pattern matched the observations based on the primer design screening, with which we found many monomorphic loci/population combinations (Arias et al. 2013). Microsatellites are thought to be mostly neutral and not under purifying selection (Jarne and Lagoda 1996), so the most likely explanation for low genetic variation is a strong effect of genetic drift caused by low migration rates among populations and low effective population size.

$\mathrm{N}_{\mathrm{e}}$ was low based on 2 estimation methods. Point estimates based on the ABC method (Tallmon et al. 2008) were much smaller than estimates based on the LD method (Do et al. 2014), but both estimates were $<50$. In conservation genetics, populations with $\mathrm{N}_{\mathrm{e}}<50$ have been flagged as having significantly increased risk of extinction because of inbreeding and reduced adaptive potential (Franklin 1980, Jamieson and Allendorf 2012).

Genetic variation was lower for G. marmoratus than for other species in the upper Murray-Darling basin (MDB). In the more arid and low-relief Moonie River, Tandanus tandanus (Mitchell 1838) and Macquaria ambigua (Richard- son 1845) had much higher within-sites genetic variation for microsatellites (Huey et al. 2011) than did G. marmoratus. Microsatellite variation was higher in populations of M. ambigua in the Condamine River, downstream from our study area, than for G. marmoratus, but mtDNA diversity was comparable (Faulks et al. 2010a, b). Populations of all of the aforementioned species are found throughout the MDB, and local populations are abundant. Furthermore, these catchments have low relief and are strongly affected by decadal flood events, which cause them to be highly connected throughout the river network. In contrast, low mtDNA genetic variation similar to that in G. marmoratus has been observed for Mogurnda adspersa (Castelnau 1878) in the Condamine catchment (Faulks et al. 2008). Mogurnda adspersa is listed as endangered in the upper MDB because of low population sizes and a patchy distribution.

Our study is the first investigation of genetic variation in cold-water adapted freshwater fish species from the upper $\mathrm{MDB}$, and the low diversity observed for G. marmoratus may reflect the highly isolated nature of this population or fragmented subpopulations that exist in disturbance-prone environments. An alternative explanation is that the species may exhibit naturally low genetic variation, as has been observed in other parts of its distribution (Arias et al. 2013). Studies on the similarly isolated population of the cold-water adapted Mountain Galaxias, Galaxias olidus (Gunther, 1866), in the upper Condamine River would be a useful complement to our study of G. marmoratus.

Overall, our findings suggest that the capacity for G. marmoratus to adapt locally to a changing environment is limited because the standing variation required for local adaptation is often insufficient in small populations. Thus, the long-term viability of the species may depend on its capacity for dispersal to new environments that are more suitable. 


\section{Populations of G. marmoratus are highly structured}

Genetic structure among populations of G. marmoratus in the Condamine River and Spring Creek is strong. Based on microsatellites, significant $F_{\mathrm{ST}}$ values were observed for almost all population comparisons. mtDNA failed to reveal such high genetic structure but had reduced power to detect genetic structure because of low genetic variation. Despite this, 14 of 21 pairwise comparisons were significantly different from 0 .

Strong genetic structure among sampled sites indicates that gene flow among populations is very low, and that the strong influence of genetic drift is causing allele frequencies to diverge. The molecular data support observations in the field that G. marmoratus is highly territorial and individuals do not move far from their small home range (Koster and Crook 2008). Furthermore, it suggests that the large demersal eggs, which are laid under rocks and logs, are not displaced. Low displacement of eggs and high likelihood of larvae remaining in their natal habitat (Koehn and O'Connor 1990a) suggest that the chance of individuals dispersing and reproducing in new areas is low. The dispersal abilities of larval and juvenile G. marmoratus have not been studied, but gene flow could be maintained through passive downstream or active upstream dispersal of these life stages. Given their early life-history attributes, the only real chance of downstream displacement probably would occur under high-flow scenarios. If so, we could expect size distributions skewed toward smaller fish in down- than in upstream habitats after large floods. Repeat sampling of our study sites $1 \mathrm{y}$ after a major flood in December/January 2010 revealed no such pattern (SRB, unpublished data). Juveniles were absent across all sites, suggesting recruitment failure under such conditions. Moreover, our results suggest any dispersal in either direction is not leading to gene flow among populations.

We used Bayesian clustering to assess whether sampling sites could be grouped into populations with shared ancestry and found support for 3 clusters, with 1 cluster at every site. However, similar clusters were not found at adjacent sites along the river. Rather, the 3 upland sites $(1,2$, and 6$)$ belonged to a single cluster, even though the only opportunity for gene flow among them was through downstream sites that belonged to another cluster. Contemporary gene flow is absent, so shared ancestry in the recent past is the most likely explanation for this result. For freshwater fish, patterns of genetic structure that do not match contemporary drainage patterns can arise from historical drainage rearrangements (Waters et al. 2001, Poissant et al. 2005). For example, in the tropical streams of northern Queensland, a population of Mogurnda mogurnda (Richardson 1844) was $3.4 \%$ divergent from other populations in the same drainage and was strongly related to populations in an adjacent catchment (Hurwood and Hughes 1998). The authors proposed that historical changes in drainages had facilitated colonization of the headwaters. Similarly, repeated movement across the Great Dividing Range has produced complex patterns of genetic structure and divergence among species of Hypseleotris (Thacker et al. 2007). However, we have been unable to find geological evidence for historical connectivity among headwaters at our study sites.

Humans could have translocated populations of G. marmoratus into headwaters. This fish has been targeted historically by local anglers, but is now protected as a no-take species. Locals could have moved the species into previously uninhabited streams above waterfalls to provide sport. Results from BayesAss suggest that sites 1 and 2 may support translocated populations that were at least partly sourced from sites 6 and 7. While sampling for G. marmoratus, we caught a 213-mm introduced salmonid (Oncorhynchus mykiss Walbaum, 1792), demonstrating the ability of humans to alter natural distributional patterns when stocking fish for angling.

Lowland sites 4, 5, and 7 clustered together, matching expectations that some gene flow would occur among sites that are not separated by waterfalls and drainage relief. Estimates of unidirectional gene flow based on BayesAss support this expectation. Despite significant differentiation, significant gene flow from site 7 to sites 4 and 5 (measured as $F_{\mathrm{ST}}$ ) was detected. However, overall, G. marmoratus appears to have restricted dispersal ability and is unlikely to be able to disperse to new environments in response to a changing climate.

\section{Conservation implications}

For G. marmoratus, threats to the upper Condamine population are exacerbated by basic features of its biology and behavior, particularly its site fidelity and restriction to cooler headwaters in warm latitudes (Koehn and O'Connor 1990b, Lintermans 2007). This restriction to cooler waters is likely to leave G. marmoratus vulnerable to climate change (Balcombe et al. 2011, Bond et al. 2011), and ongoing research on this population suggests that their current distribution is strongly influenced by high stream temperatures (M. Turschwell, Griffith University, unpublished data). The small effective population size and low genetic variation of G. marmoratus make it unlikely that the species will adapt locally to a changing environment, and the very low levels of gene flow in this species implies restricted dispersal capacity. Therefore, it is at considerable risk of local extinction because it will be unable to respond to a changing climate by colonizing new areas. The species already is restricted to a tiny upland region with no connectivity to adjacent upland areas in other catchments, and may be incapable of dispersing even within this small, hydrologically connected area.

Subpopulations of G. marmoratus were more connected in the lowland part of our study area below the major waterfalls than at upland sites. However, the lowland area is more threatened by human impacts than is the upland area. Land clearing, riparian vegetation clearing, and altered thermal re- 
gimes are all more severe in lowland than in the upland parts of the catchment. Riparian vegetation is important for shading the creek, and the persistence of dense canopy in the Main Range National Park, situated upstream of Queen Mary Falls, probably buffers downstream sites to a certain extent from thermal fluctuations. Given the reduced capacity of this population to extend its range or adapt to local changes, further research is required to determine how the distribution of this population may change in response to a changing climate and changing hydrological regimes. Such research should encompass the probability of successful revegetation of riparian areas and restoration of habitat for moderating stream temperatures, particularly where they are above or close to the upper thermal limits of G. marmoratus.

Should local extinction of a subpopulation occur within the upper-Condamine population of G. marmoratus, our data could be used to inform potential restocking. Broodstock should be taken from a genetically similar subpopulation. However, if inbreeding depression compromises those populations, then taking broodstock from multiple subpopulations may provide more resilience. If the entire upperCondamine population becomes extinct, then reference should be made to broader phylogeographic patterns across the entire MDB to identify potential sources for restocking (Hammer et al. 2014).

In conclusion, our data highlight the need for more research on this isolated population of G. marmoratus to identify and mitigate threats to their long-term persistence. With little potential to adapt or disperse in response to stressors, the survival of this population will require ongoing monitoring and management.

\section{ACKNOWLEDGEMENTS}

Author contributions: JAH, SRB, DS, and JMH conceived and designed the study. JAH, SRB, and DS carried out fieldwork, while laboratory analysis was carried out by KMR. JAH performed the statistical treatment, while interpretation and writing was carried out by JAH, SRB, DS, and JMH.

We thank Lara Coutts and Jon Marshall for field assistance and the various landowners who provided access to their properties. Funding was provided by Condamine Alliance, Inc. through their River Rescue Programme. The sampling procedures were conducted according to the requirements of the Queensland Fisheries Act 1994 under a General Fisheries Permit (Permit No. PRM0015K). All methods were also conducted according to animal ethics guidelines under a Griffith University animal ethics permit: ENV/09/10/ AEC.

\section{LITERATURE CITED}

Aljanabi, S. M., and I. Martinez. 1997. Universal and rapid saltextraction of high quality genomic DNA for PCR-based techniques. Nucleic Acids Research 25:4692-4693.

Arias, M., C. Atteke, S. Augusto, J. Bailey, P. Bazaga, L. B. Beheregaray, L. Benoit, R. Blatrix, C. Born, and R. Brito. 2013.
Permanent genetic resources added to Molecular Ecology Resources Database 1 February 2013-31 March 2013. Molecular Ecology Resources 13:760-762.

Arp, C. D., and T. Simmons. 2012. Analyzing the impacts of offroad vehicle (ORV) trails on watershed processes in WrangellSt. Elias National Park and Preserve, Alaska. Environmental Management 49:751-766.

Balcombe, S. R., F. Sheldon, S. J. Capon, N. R. Bond, W. L. Hadwen, N. Marsh, and S. J. Bernays. 2011. Climate-change threats to native fish in degraded rivers and floodplains of the MurrayDarling Basin, Australia. Marine and Freshwater Research 62: 1099-1114.

Bond, N., J. Thomson, P. Reich, and J. Stein. 2011. Using species distribution models to infer potential climate change-induced range shifts of freshwater fish in south-eastern Australia. Marine and Freshwater Research 62:1043-1061.

Chu, C., N. E. Mandrak, and C. K. Minns. 2005. Potential impacts of climate change on the distributions of several common and rare freshwater fishes in Canada. Diversity and Distributions 11:299-310.

Clement, M., D. Posada, and K. A. Crandall. 2000. TCS: a computer program to estimate gene genealogies. Molecular Ecology 9:1657-1659.

Cook, B. D., M. J. Kennard, K. Real, B. J. Pusey, and J. M. Hughes. 2011. Landscape genetic analysis of the tropical freshwater fish Mogurnda mogurnda (Eleotridae) in a monsoonal river basin: importance of hydrographic factors and population history. Freshwater Biology 56:812-827.

DeWoody, J., and J. Avise. 2000. Microsatellite variation in marine, freshwater and anadromous fishes compared with other animals. Journal of Fish Biology 56:461-473.

Do, C., R. S. Waples, D. Peel, G. Macbeth, B. J. Tillett, and J. R. Ovenden. 2014. NeEstimator v2: re-implementation of software for the estimation of contemporary effective population size (Ne) from genetic data. Molecular Ecology Resources 14:209214.

Earl D. A. 2012. STRUCTURE HARVESTER: a website and program for visualizing STRUCTURE output and implementing the Evanno method. Conservation Genetics Resources 4:359-361.

Evanno, G., S. Regnaut, and J. Goudet. 2005. Detecting the number of clusters of individuals using the software STRUCTURE: a simulation study. Molecular Ecology 14:2611-2620.

Excoffier, L., and H. E. Lischer. 2010. Arlequin suite ver 3.5: a new series of programs to perform population genetics analyses under Linux and Windows. Molecular Ecologv Resources 10:564567.

Faulks, L. K., D. M. Gilligan, and L. B. Beheregaray. 2008. Phylogeography of a threatened freshwater fish (Mogurnda adspersa) in eastern Australia: conservation implications. Marine and Freshwater Research 59:89-96.

Faulks, L. K., D. M. Gilligan, and L. B. Beheregaray. 2010a. Clarifying an ambiguous evolutionary history: range-wide phylogeography of an Australian freshwater fish, the golden perch (Macquaria ambigua). Journal of Biogeography 37:1329-1340.

Faulks, L. K., D. M. Gilligan, and L. B. Beheregaray. 2010b. Islands of water in a sea of dry land: hydrological regime predicts genetic diversity and dispersal in a widespread fish from Australia's arid zone, the golden perch (Macquaria ambigua). Molecular Ecology 19:4723-4737. 
Ficke, A. D., C. A. Myrick, and L. J. Hansen. 2007. Potential impacts of global climate change on freshwater fisheries. Reviews in Fish Biology and Fisheries 17:581-613.

Franklin, I. R. 1980. Evolutionary change in small populations Pages 135-149 in M. E. Soulé (editor). Conservation biology: an evolutionary-ecological perspective. Sinauer Associates, Sunderland, Massachusetts.

Hammer, M. P., P. J. Unmack, M. Adams, T. A. Raadik, and J. B. Johnson. 2014. A multigene molecular assessment of cryptic biodiversity in the iconic freshwater blackfishes (Teleostei: Percichthyidae: Gadopsis) of south-eastern Australia. Biological Journal of the Linnean Society 111:521-540.

Hein, C. L., G. Öhlund, and G. Englund. 2011. Dispersal through stream networks: modelling climate-driven range expansions of fishes. Diversity and Distributions 17:641-651.

Herbst, D. B., M. T. Bogan, S. K. Roll, and H. D. Safford. 2012. Effects of livestock exclusion on in-stream habitat and benthic invertebrate assemblages in montane streams. Freshwater Biology 57:204-217.

Hickling, R., D. B. Roy, J. K. Hill, R. Fox, and C. D. Thomas. 2006. The distributions of a wide range of taxonomic groups are expanding polewards. Global Change Biology 12:450-455.

Huey, J. A., D. J. Schmidt, S. R. Balcombe, J. C. Marshall, and J. M. Hughes. 2011. High gene flow and metapopulation dynamics detected for three species in a dryland river system. Freshwater Biology 56:2378-2390.

Hughes, J., S. Bunn, D. Kingston, and D. Hurwood. 1995. Genetic differentiation and dispersal among populations of Paratya australiensis (Atyidae) in rainforest streams in southeast Queensland, Australia. Journal of the North American Benthological Society 14:158-173.

Hughes, J., S. Bunn, D. Hurwood, S. Choy, and R. Pearson. 1996. Genetic differentiation among populations of Caridina zebra (Decapoda: Atyidae) in tropical rainforest streams, northern Australia. Freshwater Biology 36:289-296.

Hughes, J. M., J. A. Huey, and D. J. Schmidt. 2013. Is realised connectivity among populations of aquatic fauna predictable from potential connectivity? Freshwater Biology 58:951-966.

Hurwood, D., and J. Hughes. 1998. Phylogeography of the freshwater fish, Mogurnda adspersa, in streams of northeastern Queensland, Australia: evidence for altered drainage patterns. Molecular Ecology 7:1507-1517.

Hurwood, D. A., and J. M. Hughes. 2001. Nested clade analysis of the freshwater shrimp, Caridina zebra (Decapoda: Atyidae), from north-eastern Australia. Molecular Ecology 10:113-125.

Isaak, D., S. Wollrab, D. Horan, and G. Chandler. 2012. Climate change effects on stream and river temperatures across the northwest US from 1980-2009 and implications for salmonid fishes. Climatic Change 113:499-524.

Jamieson, I. G., and F. W. Allendorf. 2012. How does the 50/500 rule apply to MVPs? Trends in Ecologv and Evolution 27:578584.

Jarne, P., and P. J. Lagoda. 1996. Microsatellites, from molecules to populations and back. Trends in Ecology and Evolution 11: 424-429.

Kelson, S. J., A. R. Kapuscinski, D. Timmins, and W. R. Ardren. 2014. Fine-scale genetic structure of brook trout in a dendritic stream network. Conservation Genetics 16:1-12.
Kirkpatrick, M., and P. Jarne. 2000. The effects of a bottleneck on inbreeding depression and the genetic load. American Naturalist 155:154-167.

Koehn, J., and W. O'Connor. 1990a. Biological information for management of native freshwater fish in Victoria. Arthur Rylah Institute for Environmental Research, Freshwater Fish Management Branch, Department of Conservation and Environment, Heidelberg, Australia. (Available from: http://trove.nla.gov.au /work/6187373?selectedversion $=$ NBD7459400)

Koehn, J., and W. O'Connor. 1990b. Threats to Victorian native freshwater fish. Victorian Naturalist 107:5-12.

Koster, W., and D. Crook. 2008. Diurnal and nocturnal movements of river blackfish (Gadopsis marmoratus) in a southeastern Australian upland stream. Ecology of Freshwater Fish $17: 146-154$

Lintermans, M. 2007. Fishes of the Murray-Darling Basin: an introductory guide. Murray-Darling Basin Commission, Canberra, Australia.

McGlashan, D., and J. Hughes. 2000. Reconciling patterns of genetic variation with stream structure, earth history and biology in the Australian freshwater fish Craterocephalus stercusmuscarum (Atherinidae). Molecular Ecology 9:1737-1751.

Miller, A. D., G. Waggy, S. G. Ryan, and C. M. Austin. 2004. Mitochondrial $12 \mathrm{~S}$ rRNA sequences support the existence of a third species of freshwater blackfish (Percicthyidae: Gadopsis) from south-eastern Australia. Memoirs of Museum Victoria 61:121-127.

Nilsson, C., C. A. Reidy, M. Dynesius, and C. Revenga. 2005. Fragmentation and flow regulation of the world's large river systems. Science 308:405-408.

Page, T., and J. Hughes. 2010. Comparing the performance of multiple mitochondrial genes in the analysis of Australian freshwater fishes. Journal of Fish Biology 77:2093-2122.

Palmer, M. A., C. A. Reidy Liermann, C. Nilsson, M. Flörke, J. Alcamo, P. S. Lake, and N. Bond. 2008. Climate change and the world's river basins: anticipating management options. Frontiers in Ecology and the Environment 6:81-89.

Poff, N. L., J. D. Olden, and D. L. Strayer. 2012. Climate change and freshwater fauna extinction risk. Pages 309-336 in L. Hannah (editor). Saving a million species. Island Press, Washington, DC.

Poissant, J., T. W. Knight, and M. M. Ferguson. 2005. Nonequilibrium conditions following landscape rearrangement: the relative contribution of past and current hydrological landscapes on the genetic structure of a stream-dwelling fish. Molecular Ecology 14:1321-1331.

Ponniah, M., and J. M. Hughes. 2006. The evolution of Queensland spiny mountain crayfish of the genus Euastacus. II. Investigating simultaneous vicariance with intraspecific genetic data. Marine and Freshwater Research 57:349-362.

Pritchard, J. K., M. Stephens, and P. Donnelly. 2000. Inference of population structure using multilocus genotype data. Genetics 155:945-959.

Swift, L. W., and J. B. Messer. 1971. Forest cuttings raise temperatures of small streams in the southern Appalachians. Journal of Soil and Water Conservation 26:111-116.

Szpiech, Z. A., M. Jakobsson, and N. A. Rosenberg. 2008. ADZE: a rarefaction approach for counting alleles private to combinations of populations. Bioinformatics 24:2498-2504. 
Tallmon D. A., A. Koyuk, G. Luikart, and M. A. Beaumont. 2008. COMPUTER PROGRAMS: ONeSAMP: a program to estimate effective population size using approximate Bayesian computation. Molecular Ecology Resources 8:299-301.

Thacker, C. E., P. J. Unmack, L. Matsui, and N. Rifenbark. 2007. Comparative phylogeography of five sympatric Hypseleotris species (Teleostei: Eleotridae) in south-eastern Australia reveals a complex pattern of drainage basin exchanges with little congruence across species. Iournal of Biogeography 34: 1518-1533.

Wang, J., W. G. Hill, D. Charlesworth, and B. Charlesworth. 1999. Dynamics of inbreeding depression due to deleterious mutations in small populations: mutation parameters and inbreeding rate. Genetical Research 74:165-178.

Waples, R. S. 1991. Genetic interactions between hatchery and wild salmonids: lessons from the Pacific Northwest. Canadian Journal of Fisheries and Aquatic Sciences 48:124-133.
Waples, R. S., and C. Do. 2008. LDNE: a program for estimating effective population size from data on linkage disequilibrium. Molecular Ecology Resources 8:753-756.

Ward, R., M. Woodwark, and D. Skibinski. 1994. A comparison of genetic diversity levels in marine, freshwater, and anadromous fishes. Journal of Fish Biology 44:213-232.

Waters, J. M., D. Craw, J. H. Youngson, and G. P. Wallis. 2001. Genes meet geology: fish phylogeographic pattern reflects ancient, rather than modern, drainage connections. Evolution 55: 1844-1851.

Willi, Y., J. van Buskirk, and A. A. Hoffmann. 2006. Limits to the adaptive potential of small populations. Annual Review of Ecology, Evolution, and Svstematics 37:433-458.

Wilson, G. A., and B. Rannala. 2003. Bayesian inference of recent migration rates using multilocus genotypes. Genetics 163:1177-1191.

Wohl, E. 2006. Human impacts to mountain streams. Geomorphology 79:217-248. 